\title{
Social Risk Assessment: A Conceptual Implementation Pathway and beyond in Mainland China
}

\author{
Ze-Zhao LIU ${ }^{1, a^{*}}$, Hui-Jia WANG ${ }^{2, b}$ \\ ${ }^{1}$ School of Philosophy \& Public Management, Jiangsu Normal University, China \\ ${ }^{2}$ The People's Procuratorate of Tongshan District, Xuzhou, Jiangsu Province, China \\ apreliu@yeah.net, ${ }^{b}$ liangjiawang@126.com
}

Keywords: Social risk assessment, Local government, Framework, China.

\begin{abstract}
From historical perspective, social risk assessment is of significance for national economic development and stability. It presents the necessity and urgency to push social risk assessment in the context of a China New Era stage. Based on the chain of events theory, catastrophe and risk society theory, the paper employs to analyze the formation mechanism and evolution models of China social stability assessment enforcement, and furthermore carry out a systematic review analysis in terms of local practice. According to the actual implementation traits it presents realistic predicaments and future prospects for improvement.
\end{abstract}

\section{Introduction}

In the changing uncertain world, risk management helps people both in business and political fields make informed decisions, while organization leaders and policymakers from various fields have applied series of means to use a risk-based approach to prioritize decisions. As an emerging economies, China also faces many developmental contradictions as well as risks un the fast growing process, and political leaders are always trying to absorb effective risk management experiences ever used in the private sector. One obvious feature of Chinese risk management is the ideology of social stability maintenance, which penetrates into the government's tasks in accordance with the governance principles of the CCP. Pushing social risk assessment may be one of the profound policy measures undertaken by the Chinese government since 2010s, and certain to be of great significance to China political \& social development.

Since the initial stage of $21^{\text {th }}$ century, risk topic has turned to hot debate in the western world. Although views are different, various environmental hazards, disasters and threats are gradually attracted as risk awareness (Sharfman,2010[1]; Blanchard,2014[2]; Frankel, 2013[3]; Hutanuwatr, 2013[4]). The human society is facing unprecedented challenges in the era of globalization, and some scholars believe that we have entered a period of what is called "risk society"(Sørensen, 2018[5]). One point ought to be addressed that not only risk issue is discussed in science and technology aspects but also extend to a large social scope especially on the national security and public fields (Catlaw,2014[6]). Facing overwhelming global governmental reforms and service-oriented transformation, Shorts (1984) [7] strong appeals to the exploration perspective on the base of social transformation of risk analysis. Taking U.S as one example, risk management has been endorsed by the congress, the president, and the Secretary of DHS as a way to strengthen the nation against possible attacks. DHS has used risk management principles to invest millions of dollars at the state and local level as part of its Urban Area Security Initiative (UASI) grants [8]. Due to dependence of the economic, political, cultural and other subsystems on the social system, the risk will affect in any social area and spread to the entire community, possibly leading social unrest and instable unease(Tong, 2007[9]). Thus, modern social risks are supposed to be deeply examined in an integrated manner while getting rid of the single one-dimension perspective.

\section{China Scenario on Social Risk Assessment}

With the advancement of China's modernization and rapid changes of traditional system, the 
contemporary China is now revealing imprints of the integrated risks. The speedy accumulation of man-made risks has spread in a different tension among various groups. Emerging exacerbate unemployment, public safety, network proliferation, and social revenge are in a wide range of high incidence of momentum. On sequence spectrum of development is that China is standing on the corresponding non-steady-state space-time phase and it is the echoes of community transition as a whole. Some scholars believe that the development stage comprised of the unity in "structural transformation transition and concept change" (Liu, 2005[10]). From the historical experience in some foreign countries, social transformation risk caused by the deep structural change constitutes a threat of great instability in the society.

Owing to fast economic development, mega-events dominated by the government are increasing in great numbers, such as major public policy, major public events, and major infrastructure projects. Mega event on one hand plays a catalytic role in promoting the overall economic and social development, but on the other hand also bring severe pressures on social stability. Social stability risk assessment performed by the Chinese government is a general practice drawing on international economic security warnings with reference to develop, introduce and implement on major issues before the scientific analysis of the factors. In other words it ought to assess the likelihood of harm as well as its frequency in order to take practical measures to prevent, reduce and eliminate possible social risks. Since the policy takes into effect by the central government, local governments in all walks of fields have pushed forward in great steps and measures. Nowadays, China practice has accumulated more mature experience and formed a pattern for reference promotion and it is of great importance both academically and practically to explore its values.

China social risk assessment approach aims to measure, identify risk factors on major issues in the social system, and predict the possibility of conflicts, turmoil and its degree of harm, which is applied by the government's public sector to develop preventive decision measures for a scientific basis. Based on theoretical research and practice, we believe that the risk assessment framework or model includes assessment body, assessment scope, assessment direction, assessment process and assessment tools (see Figure 1)

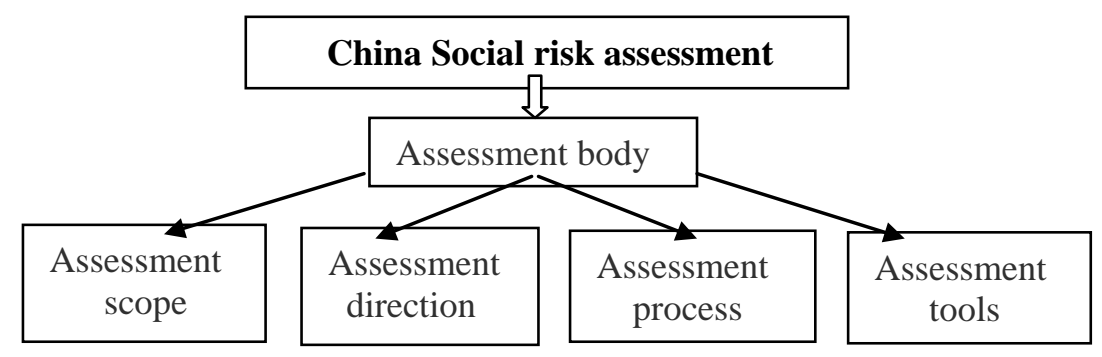

Fig 1. Basic constructed elements in social risk assessment

\section{Social Risk Assessment Program}

As the implementation of rules and resource allocation policies, social risk assessment process faces with conflicting policy environment, in which coordination should consider stakeholder preference. Social risk assessment is actually an integrated social selection process of the different preferences of interest.

In the official perspective of Chinese central government, if decisions are made by local Party and government, the assessment body should also be themselves. If decisions are made by departments of local Party and government, the assessment body should be the departments or appointed sectors. However, the whole assessment rule owns series of problems. In reality the subject of social risk assessment is often built on top of the cross-border of public interests and private interests or the process of private interests infringements. Absence of relevant stakeholders on any public assessment, the destructive effects will be unavoidable. Clashes in the state of lack of trust will more and more become the normal. Honestly, examining the social risk assessment body cannot achieve the polarity of "optimal state ", but to pursue the "satisfactory solution". From the 
background and the reality of contemporary China's development, we believe that the main feasible assessment body mode should be in a greater tendency to attract people with relevant experts, professional third-party stakeholders, public media into the assessment circle, and offer a smooth, proper, substantial expression of free speech. In other words, governments at all levels is the direct responsibility part of major issues in implementation, assessment and monitoring. Party committees, stability maintenance departments are responsible for steering the overall direction of significant matters acting as a specialization of the principal role; while relevant interest groups, third-party occupy the main checks and essential balances. Fundamentally, social risk assessment aims to be the diagnosis of risk status and an understanding the trend of stability, people's sense of identity, trust in government in order to build the interaction among government and the public.

Due to the physical geography, population dynamics, economic development and religious factors, different regions in China are in different source of risks. We believe that the current social risk assessment should be focused on the following areas: Firstly, the development of urban construction and social management of the major issues, such as urban renewal, housing demolition, utilities, price adjustment, public affairs that may cause death of the criminal cases; Secondly, resource development, countries and regions of key projects, especially those related to the considerable number of people in the vital interests of the project site, land acquisition, resettlement, and environmental pollution; thirdly, the grassroots democratic actions involving greed corruption and inducing matters; fourthly, enterprise reform and institutional reform focusing on the transfer of property rights, including the restructuring of state-owned enterprises, personnel placement, social security, personnel in the institutions of policy shunt placement, disposal of assets, benefits of major changes; Fifth, policies and reforms of social undertakings, such as the adjustment of the livelihood of pension, health care, employment, the minimum living security policy, major health epidemic warning; Sixth, regional major public activities, logistical support and emergency management.

\section{China Social Risk Assessment Implementation}

As a scientific procedure for public sector decision-making, social risk assessment generally cast focus on steps as identification, program development, and assessment. In this process, social risk assessment lays particular emphasis on a complete scientific proof and a thorough detailed program of work, attaches importance to the unified command leadership and departments under the coordination linkage of different interest groups.

\section{Social Risk Assessment Tools \& Methods}

With regards to the theoretical research and practices, social risk assessment tools or methods can be broadly divided into quantitative and qualitative types, but in a different background the context of application may be different.

The initial assessment is usually based on opinion polls, public hearings, group consultation mainly through contacting with relevant interest groups maneuver to obtain significant matters of public risk information. And then combined in a specific case analysis, it can reveal the overall risk posture of the initial decision-making. Further assessment attributable to the scientific levels of analysis, the general index evaluation and fuzzy number evaluation aimed at the sources of risk identification. In this field, we rely on the assessment model and indicator system with aid of pre-acquisition information analysis. More popular in the risk assessment methods include Monte Carlo simulation, probabilistic method, risk evaluation and technique. The data could be collected by the authoritative publications, questionnaires, scales, qualitative interviews and Delphi expert method. In this process, social stability index and the risk of the establishment of early warning indicator system is the key point, in which system simulation technology as well as interdisciplinary science contributes to realistic social scene.

\section{Practical Plight and Discussion}

After several years of regional exploration, social risk assessment has begun to obtain group identity. 
However, China existing system remain multiple obstructions to impede this initiative.

\section{Accountability Structures}

Institutional characteristics suggests that political accountability is essential for public sector in China. Under the existing system, although the responsibility of party and government leaders gradually remain standardized, it still stays at the principle level, there are conflicts in the accountability object, standards, intensity and effectiveness. Social risk assessment professional are often characterized by cross vague so that the main responsibility attribution is hard to identify. In addition, as the typical risk of accountability should not only concern about the routine duties of certain officials, but also need to ask the deep levels of the institution, namely "responsible for the policies, responsible for the structure and responsible for the value of responsibility” (Tong 2007).

\section{Assessment Scientific Issue}

With Chinese characteristics social risk assessment belongs to the public policy measures. One fact is the operation time is relatively shorter, especially the process and tool cannot form a unified model, We can learn from some of the practices of the western economic risk and corporate risk control principle, but it is impossible to simply copy these actions. Due to a lack of objective quantitative criteria for the risk of social stability the real impact of China's social stability factors are very complex, therefore the indicator of the current design evaluation tool appears to be biased inadequacies. One thing is clear that we should adhere to the strategy and tactics, the combination of qualitative and quantitative in social risk assessment methods, as is a more rational pathway.

\section{Administrative Mode and Focus}

From the administrative sequence point of view, China is divided into five levels, namely central, provincial, municipal, county and township. Every level is great different in strategic focus, value-driven system, executive direction and specific development goals related to social stability. Without realistic assessment of the entities, social risk assessment will inevitably make the policy innovation reduce to the image of official performance engineering, and thus contrary to the original reform intention.

\section{Conclusion}

Learning from foreign government experience, social risk management has been standing in a major strategic position, which is related to targets of a country development and the ruling party. Keeping relative social stability is of great significance and serves as one vital development goal for all the governments. As one major institutional innovation eventually recognized by the national higher decision-makers as a local bottom-up drive in risk management, China social risk assessment owns the world originality. Though the exploration in the theory and practice remains for a less period of time, it leaves aspects of doubts and difficulties. In China's special background and governmental framework, we believe, to effectively push social risk assessment is inseparable from China system within, especially the deep cognitive exploration of the social stability of theoretical framework as well as traditional political culture. Nowadays, China's economic and social development has entered the New Era, as put forward in CCP's $19^{\text {th }}$ National Congress in 2017, the implementation of social risk assessment would be certain to provide a strategic significance in mainland China.

\section{Acknowledgement}

This paper was supported by general Social Science Fund of Shaanxi Province in China (2016R016) and China National Social Science Foundation (17BZZ039).

\section{References}

[1] Sharfman, M. P., \& Fernando, C. S. (2010). Environmental risk management and the cost of 
capital. Strategic Management Journal,29(6), 569-592.

[2] Blanchard, C. S. (2014). Changing the face of the earth: the morrison-knudsen corporation as partner to the U.S. federal government. Dissertations \& Theses - Gradworks, 4(1).

[3] Frankel, JA. (2013). The environment and globalization. NBER Working Papers, 55(2), 161-210.

[4] Hutanuwatr, K., Bolin, B., \& Pijawka, D. (2013). Vulnerability and Disaster in Thailand: Scale, Power, and Collaboration in Post-tsunami Recovery. Forces of Nature and Cultural Responses. Springer Netherlands.

[5] Sørensen, M. P. (2018). Ulrich beck: exploring and contesting risk. Journal of Risk Research, 21(2), 1-11.

[6] Catlaw, TJ. (2014). Frederick Thayer and the Structural Transformation of the Public Sphere. Administration \& Society, 40(4), 358-383.

[7] Short, J. F. (1984). The social fabric at risk: toward the social transformation of risk analysis. American Sociological Review, 49(6), 711-725.

[8] Applying Risk Management Principles to Guide Federal Investments. DHS. GAO-2007-386T.

[9] Xing T. Social Risks and Identifications in China's Transition-Theoretical Discussion and Empirical Research. Nanjing University Press, China. 2007. pp.89. (in Chinese)

[10]Liu Zuyun. Interpretation of Social Transformation. Wuhan University Publishing House, China. 2005,pp.26. (in Chinese). 